\title{
Hlx homeo box gene is essential for an inductive tissue interaction that drives expansion of embryonic liver and gut
}

\author{
Bernd Hentsch, ${ }^{1}$ Ian Lyons, ${ }^{2}$ Ruili Li, Lynne Hartley, Thierry J. Lints, ${ }^{3}$ Jerry M. Adams, \\ and Richard P. Harvey ${ }^{4}$ \\ The Walter and Eliza Hall Institute of Medical Research, Post Office, Royal Melbourne Hospital, Victoria 3050, Australia
}

The divergent murine homeo box gene $\boldsymbol{H l x}$ is expressed in restricted hematopoietic cell types and, during embryogenesis, prominently in visceral mesenchyme of the developing liver, gall bladder, and gut. Targeted disruption of the gene has now established that it plays a key role in visceral organogenesis. Embryos homozygous for the mutation died around embryonic day 15 with anemia and severe hypoplasia of the liver and gut. Liver ontogeny commenced normally with formation of the liver diverticulum and differentiation of hepatocytes, but the organ failed to expand and reached only $3 \%$ of normal size. The apparent liver hypoplasia was not associated with a notable increase in apoptotic cells. Gut development also began normally, but the intestines failed to undergo extensive elongation and looping and reached only a quarter of normal length. The anemia resulted from a deficiency in the fetal form of hematopoiesis, which occurs in the liver, but no intrinsic defect in $\mathrm{Hlx}^{-1-}$ hematopoietic cells was observed in vitro, and liver-derived $\mathrm{Hlx}^{-1-}$ hematopoietic stem cells that were transplanted to irradiated normal mice could fully reconstitute hematopoiesis. The impaired fetal hematopoiesis therefore reflects insufficient support function provided by the minute liver. $H \mathbf{x}$ is normally expressed in visceral mesenchyme lying adjacent to the developing liver and gut epithelia affected by the mutation, but not in the epithelia themselves. Hence, HIx regulates a mesenchymal-epithelial interaction that drives a vital growth phase in visceral organogenesis. Moreover, because mutation of $\mathbf{H l x}$ blocked liver growth but not its specification, early morphogenesis, or differentiation, development of this organ appears to occur by step-wise inductive interactions under separate genetic control.

[Key Words: Homeo box gene; organogenesis; liver; gut; hematopoiesis; gene targeting]

Received September 18, 1995; revised version accepted November 2, 1995.

Transcription factors bearing the homeo domain govern a growing spectrum of developmental processes. In mammals, members of the four conserved clusters of Hox genes specify position along the axes of the embryo and limbs (Krumlauf 1994), whereas certain of the unclustered and more divergent homeo box genes have been assigned roles in growth control, organogenesis, or establishment of cellular phenotype (Lin et al. 1992; Corcoran and Karvelas 1994; Jonsson et al. 1994; Roberts et al. 1994; Halder et al. 1995; Lyons et al. 1995). The murine $H l x$ gene, a member of the divergent class, was first detected via its expression in hematopoietic cells of the myelomonocytic and B lymphocyte lineages (Allen et al. 1991). Enforced overexpression of $H l x$ (or its human homolog $H L X / H B 24$ ) in hematopoietic cell lines (Deguchi et al. 1992; Allen and Adams 1993) as well as in lym-

Present addresses: ${ }^{1}$ Deutsches Krebsforschungszentrum, D-69120 Heidelberg, Germany; ${ }^{2}$ Bresatec Ltd., Thebarton 5031 Australia; ${ }^{3}$ Department of Physiology and Cellular Biophysics, Columbia University, New York, New York 10032 USA

${ }^{4}$ Corresponding author. phocytes of transgenic mice (Allen et al. 1995; Deguchi et al. 1993) led to alterations in differentiated phenotype, but no clear picture of its biological role in normal hematopoiesis has emerged.

During embryogenesis, $H l x$ is expressed in tissues of mesodermal origin, notably in visceral mesenchyme, skeletal myoblasts, sclerotome and limb mesenchyme (Allen et al. 1991; Lints et al. 1996). The restriction of expression to subsets of individual lineages suggests a role for the gene in tissue growth or patterning (Lints et al. 1996). Hlx expression commences around embryonic day 9-5 (E9.5) in splanchnic mesoderm of the midgut and hindgut and from E10.5 to E12.5 is prominent in mesenchyme of the developing liver, gall bladder, and gut. The structure and visceral expression of $H l_{\mathrm{X}}$ resemble those of the Drosophila homeo box gene H2.O (Barad et al. 1988 l, implicating $H l_{x}$ in a conserved aspect of visceral development.

Generation of all the viscera is known to depend critically on inductive interactions between mesenchyme and adjacent epithelia (Birchmeier and Birchmeier 1993). 
Although these developmental processes have long been studied, particularly in the liver (Le Douarin 1975; Houssaint 1980), pancreas (Wessells and Cohen 1967; Rutter et al. 1978), and kidney (Grobstein 1953; Bard 1992), only recently has any genetic purchase on their molecular control been gained (Kriedberg et al. 1993; Jonsson et al. 1994). For liver development, at least two inductive interactions are required (Zaret 1994; Le Douarin 1975; Houssaint 1980). First, a liver fate is specified within midgut endoderm by contact with cardiogenic mesoderm. Second, contact with the septum transversum, a mesenchyme located at the base of the heart, provokes an epithelial-mesenchymal transition within the liver anlage; this tissue interaction is essential for formation of the liver diverticulum and later of the liver bud, as well as its further expansion and differentiation (Le Douarin 1975; Houssaint 1980).

To date, almost nothing has been established about the genetic control of liver ontogeny. By targeted disruption of the $H l_{x}$ gene, we have now found that $H l_{x}$ is essential for the vital expansion phase in liver as well as gut development. By mid-gestation, embryos homozygous for an interruption of the HIx homeo box exhibited severe hypoplasia of liver and gut epithelia. Because the gene is normally expressed in mesenchyme surrounding the affected epithelia (Lints et al. 1996), these findings prompt the proposal that Hlx governs expression of a mesenchymal signal that drives expansion of liver and gut epithelia during organogenesis. The results also suggest that visceral organogenesis proceeds by stepwise inductive interactions under separate genetic control.

\section{Results}

\section{Hlx is vital for visceral development}

To disrupt the Hlx gene by homologous recombination, a replacement-type targeting vector (Thomas and Cappechi 1987) with a critical portion of the homeo box deleted (Fig. 1a) was electroporated into E14 embryonic stem (ES) cells (Hooper et al. 1987). The gene was disrupted in the expected way in 5 of 200 ES cell clones analyzed and, following injection into blastocysts, one clone proved to transmit the mutant allele through the germ line (see Materials and methods). Mice and embryos from this line were genotyped by Southern blotting or PCR (Fig. 1b). The engineered mutation very likely creates a null allele, because disruption of helix 3 of the homeo domain would eliminate DNA binding. Whether the predicted truncated protein is produced has not been determined.

Animals heterozygous for the mutant allele developed normally, were fertile, and enjoyed long life. Newborn litters from heterozygous crosses, however, contained no homozygous progeny ( 0 of 216). Analysis of fetuses at progressively earlier times revealed that homozygotes invariably died around E15. Through E15, the homozygotes represented the expected Mendelian ratio of one quarter of progeny (88 of 326). $a$

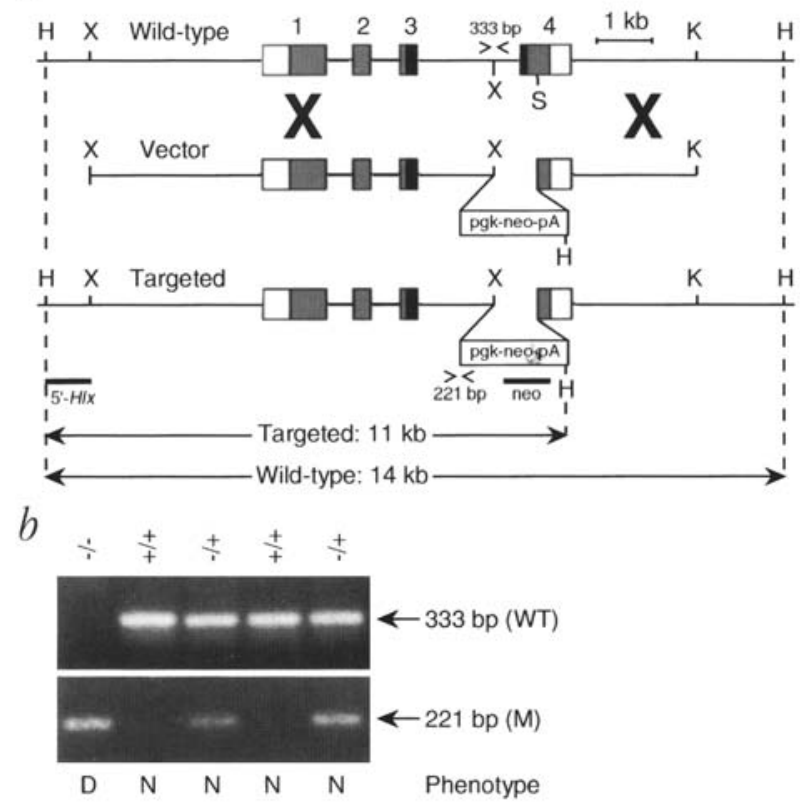

Figure 1. Targeting strategy for the $H l x$ locus and genotype analysis. $(a)$ Wild-type $H l x$ locus, targeting vector, and targeted locus. Exons are boxed with coding regions shaded and the homeo box filled. In the vector, which has $7.5 \mathrm{~kb}$ of Hlx sequences in its left arm and $2.8 \mathrm{~kb}$ in its right, a neo ${ }^{\mathrm{R}}$ expression cassette containing a phosphoglycerol kinase- 1 promoter and polyadenylation signal replaces an XbaI-SacII fragment encoding amino acids $45-61$ of the homeo box and sequences immediately downstream. Bars indicate probes used to characterize targeting events by Southern blotting, and brackets indicate PCR primers. (b) The PCR analysis used to genotype embryos and adult mice. Products generated with primer pairs specific for the wild-type (WT) and mutant (M) alleles (see above) were resolved on an agarose gel. The defective phenotype (D) correlated entirely with the $-/-$ genotype and the normal $(N)$ with $+/-$ or $+/+$ genotypes.

Before death, $\mathrm{Hl}_{\mathrm{x}^{-1-}}$ embryos were normal in size and general body plan but all were pallid, indicative of anemia, and displayed a characteristic visceral pathology. Removal of the body wall at E14.5 invariably showed a minute liver (cf. Fig. 2a,b). Its small size was also evident upon dissection of the digestive tract at E13.5, which revealed further that the intestines were only a quarter of the normal length (Fig. 2c). This marked pathology was evident in all $84 \mathrm{E} 10.5-\mathrm{E} 14.5 \mathrm{Hlx}^{-1-} \mathrm{em}$ bryos examined macroscopically as well as the 13 subjected to histological analysis (see Materials and methods).

\section{Normal differentiation but blocked proliferation in the liver}

Liver ontogeny commences on $\mathrm{E} 9$ when an endodermal diverticulum of the midgut proliferates into the mesenchyme of the septum transversum in response to mesenchymal signals (Le Douarin 1975; Houssaint 1980). At 


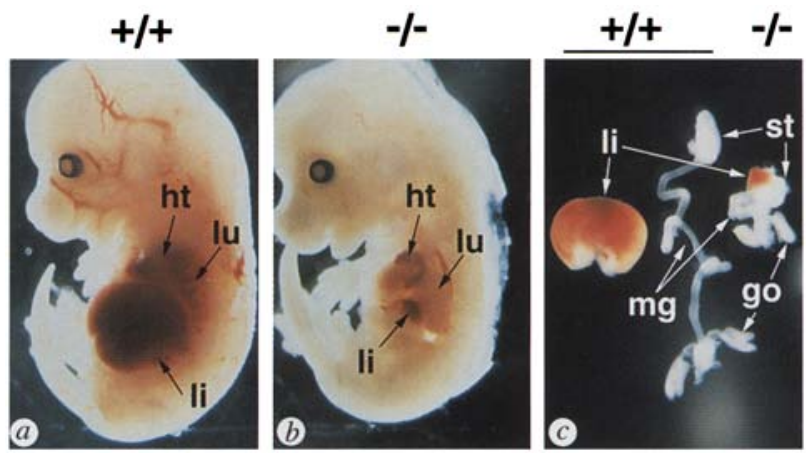

Figure 2. Wild-type and $H \mathrm{x}^{-1-}$ embryos and their visceral organs. $\{a, b\}$ E14.5 embryos with left body wall removed to display the viscera. (c) Dissected liver and digestive tract, from the stomach to the cloaca, of E13.5 embryos. Abbreviations: (go) Gonads; (ht) heart; (li) liver; (lu) lung; (mg) midgut, and (st) stomach.

E9.5, $\mathrm{Hl}^{-1-}$ embryos exhibited a normal liver diverticulum and liver cords (compare Figs. 3a,b). At E10.5, however, no liver bud had yet formed in mutants, the organ remaining a mere cluster of hepatocytes within the septum transversum (Fig. 3, cf. d and f). At E14.5, when the normal liver has formed large dorsal and ventral lobes, the ventral portion of the mutant liver remained rudimentary (not shown), whereas more dorsally, a small bud had developed (Fig. 3 , cf. $g$ and h). Despite the reduced size, its general architecture and cellular composition were relatively normal, with immature hepatocytes, endothelial cells and hematopoietic cells readily discernible (Fig. 3, cf. i and j). Thus, liver specification and generation of the diverticulum appeared normal in $\mathrm{Hlx}^{-1-}$ embryos, but expansion of the organ was severely inhibited from the earliest stages of its ontogeny. Indeed at E12.5, the mutant liver contained only $3 \%$ of the normal number of cells (see Materials and methods).

In principle, the reduced size of the liver might reflect an increase in cell death rather than a decrease in proliferation. In fact, the liver is reduced in size because of apoptosis in embryos homozygous for mutations in the gene for the RelA component of NFkB (Beg et al. 1995), for the c-met cell-surface receptor (Bladt et al. 1995) or for its ligand, hepatocyte growth factor/scatter factor (HGF/SF) (Schmidt et al. 1995). The apoptotic cells readily apparent in histological sections of those livers, however, were not observed in the $\mathrm{HlX}^{-1-}$ liver (Fig. 3i). Furthermore, in cell suspensions of E12.5 liver, the proportion of viable cells (those excluding trypan blue) was no lower for mutant than normal embryos. Nevertheless, we assessed apoptosis directly in the $\mathrm{HlX}^{-1-}$ liver at E13.5 using the sensitive TUNEL in situ test for DNA fragmentation (Gavrieli et al. 1992). Apoptotic cells were no more abundant in the mutant than in normal liver (data not shown). Hence, increased cell death is unlikely to account for the minute size of the liver.

To begin to analyze the basis for the block in liver ontogeny, we explored whether development of hepatocytes was impaired. Their differentiation status was as- sessed by use of in situ hybridization to detect mRNA for the liver differentiation markers $\alpha$-fetoprotein and transthyretin (Makover et al. 1989; van den Hoff et al. 1994). Expression of these genes begins extremely early in liver development and increases progressively during ontogeny (Thomas et al. 1990). The genes were expressed at near normal levels in both the ventral rudiment and the minute dorsal lobe of the mutant liver (Fig. 4). Thus, no arrest in the hepatocyte differentiation program was evident.

\section{Abnormal intestinal growth and other visceral abnormalities}

Development of the gut, like the liver, depends critically

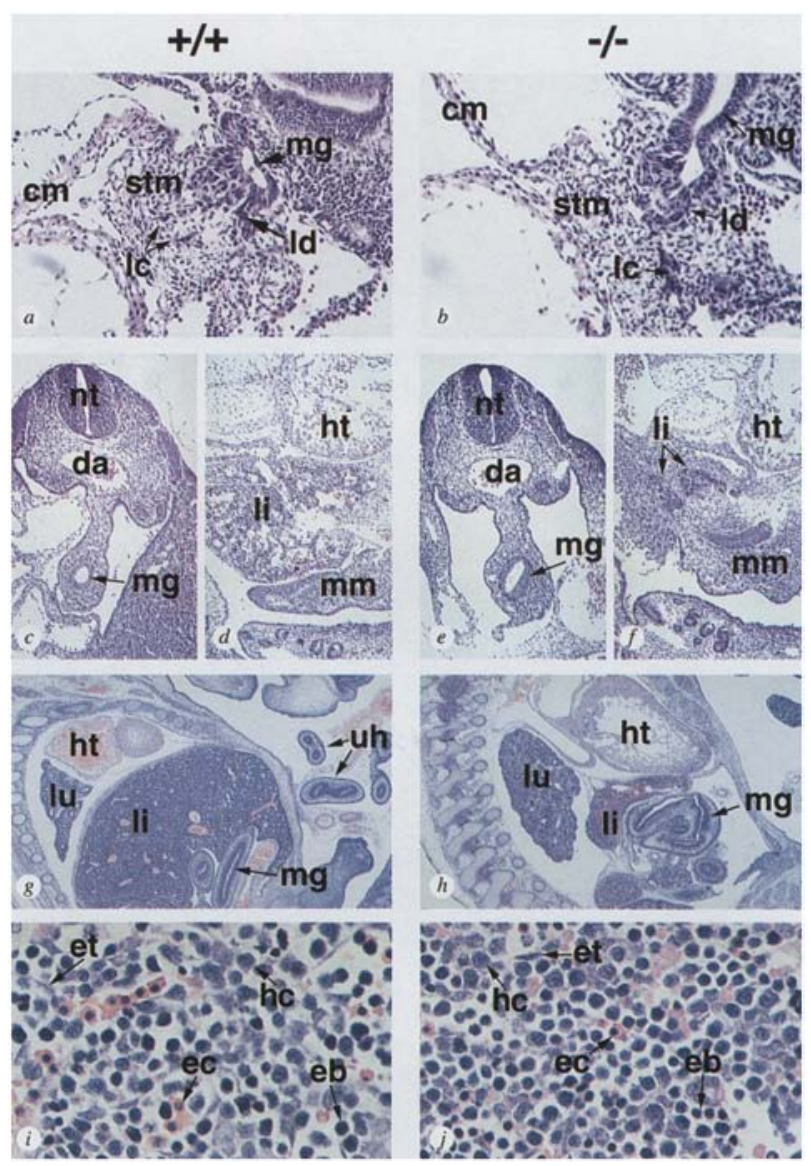

Figure 3. Histological analysis of wild-type $(+/+)$ and mutant $(-/-)$ embryos. $(a, b)$ Sections of E9.5 embryos, highlighting the liver diverticulum (ld) and liver cords (lc) growing into the septum transversum mesenchyme $(\mathrm{stm})$. $(c-f)$ Sections of E10.5 embryos, highlighting midgut $(c, e)$ and liver $(d, f)$ structures. Note the normal midgut but minute liver (li) in mutants. $\{g, h)$ Visceral region of E14.5 embryos. Mutant embryos display a minute liver, enlarged lung (lu) and abnormal compacted midgut that lacks the loops of the umbilical hernia $(u h) .(i, j)$ Liver structure in E14.5 embryos. Note presence of hepatocytes (hc), endothelial cells (et), erythrocytes (ec) and erythroblasts (eb). Other abbreviations: $(\mathrm{cm})$ cardiac mesoderm; (da) dorsal aorta; (ht) heart; (mg) midgut epithelium; (mm) midgut mesenchyme; (nt) neural tube. 


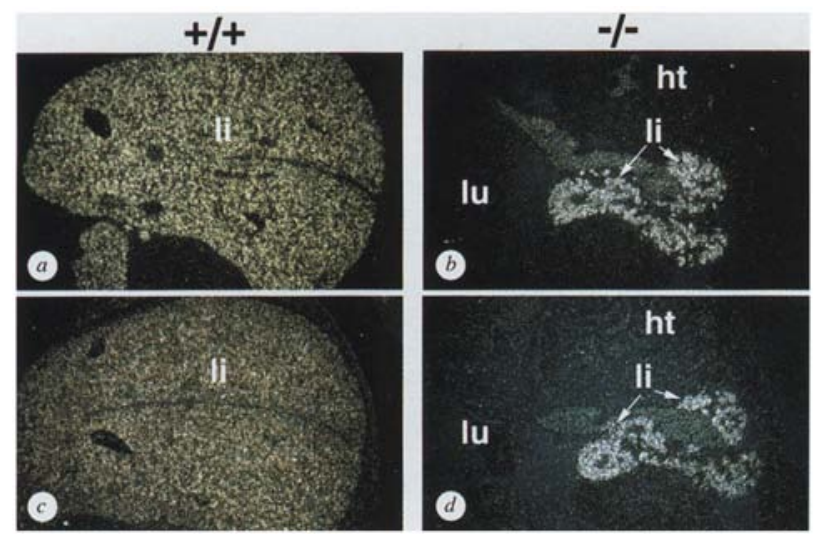

Figure 4. In situ hybridization of wild-type $(+/+)$ and mutant ()$\left.^{-}\right)$livers. E13.5 liver sections hybridized with $\alpha$-fetoprotein $(a, b)$ and transthyretin $(c, d)$ radiolabeled complementary RNA probes, transcribed from plasmids. Abbreviations: (ht) Heart; (li) liver; (lu) lung.

on communication between visceral mesenchyme and the endodermally derived epithelium (Kedinger et al. 1986; Del Buono et al. 1992; Birchmeier and Birchmeier 1993). In normal embryos, $H l_{x}$ is expressed in midgut and hindgut mesenchyme, with a sharp anterior boundary within the duodenum (Lints et al. 1996). At E10.5, the gut of $\mathrm{HlX}^{-\prime-}$ embryos appeared normal with characteristic midgut and hindgut structures (Fig. 3, cf. c and e). Its limited expansion between E11.5 and E14.5, however, was evident from the absence of the extensive looping and midgut umbilical hernia observed in normal embryos. The mutants exhibited only a single intestinal loop at E13.5 and E14.5 (Figs. 2c and 3g,h). The mesenchymal sheath surrounding the epithelia became normally stratified into histologically distinct layers, but the mesenchyme and sometimes the epithelium were fused into a compact, highly abnormal structure (Fig. $3 g, h)$.

Certain other viscera in which $H l_{x}$ is normally expressed (Lints et al. 1996) were also altered. The gall bladder, which normally develops in conjunction with the liver, was not discernible. The diaphragm contained few muscle cells and was herniated in every mutant examined. The lungs, although normal in structure, appeared enlarged and protruded through the diaphragmatic hernia into the peritoneum. Other tissues in which HIx is expressed (muscle cells, skeleton, whisker follicles), however, appeared to develop normally. Among viscera that do not express Hlx, the pancreas, which arises near the liver, was normal in structure although reduced in size, while the kidney and gonads were unaffected.

\section{Deficiency in fetal hematopoiesis}

The anemia of $H \mathrm{l}^{-1-}$ embryos, the likely cause of their death, was discernible as a reduced number of total erythrocytes in peripheral blood at E13.5 and was marked at E14.5 (Fig. 5). The anemia appears to reflect a deficiency in the fetal form of hematopoiesis, which commences in the liver around E10 and progressively supplants the embryonic form originating in the yolk sac (Dzierzak and Medvinsky 1995). Yolk sac hematopoiesis, which yields nucleated erythrocytes, seemed to be intact because the blood contained a normal concentration of those cells at E12.5-E14.5 (Fig. 5). Enucleated (liver-derived) erythrocytes, however, represented only $30 \%$ of total erythrocytes by E14.5, compared with $80 \%$ in normal embryos (Fig. 5). In the absence of robust fetal hematopoiesis, yolk sac erythropoiesis is evidently insufficient to prevent death from hypoxia at mid-gestation. Disruption of the myb gene, which is necessary for fetal but not yolk sac hematopoiesis (Mucenski et al. 1991), led to precisely the same outcome.

To examine further how the deficit in production of fetal blood cells was linked to the liver, we enumerated hematopoietic progenitors in that organ by their capacity to initiate colonies either in vitro or in the spleen of irradiated recipients. In all assays performed, $\mathrm{HlX}^{-1-}$ colonies were of normal appearance and composition. As one might expect from the minute size of the liver, how-

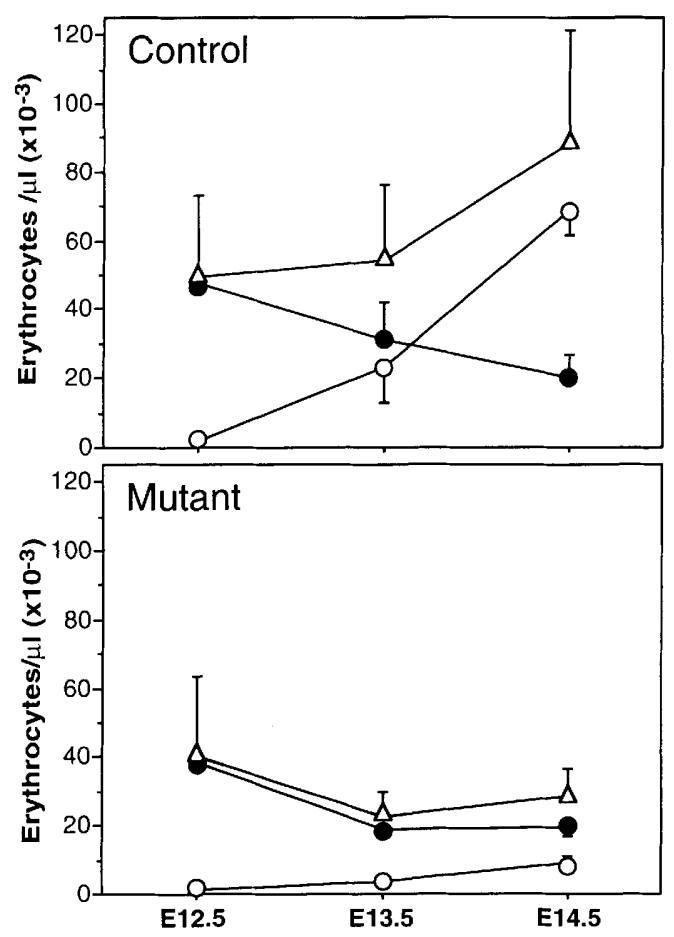

Figure 5. Reduced concentration of enucleated erythrocytes in the blood of $\mathrm{HlX}^{-1-}$ embryos. The total concentration of erythrocytes $(\Delta)$ (derived from a total of 17 control and 17 mutant embryos) and the proportion of nucleated (yolk sac-derived; and enucleated (liver-derived; O) erythrocytes (from a total of 87 control and 35 mutant embryos) were determined microscopically from blood smears at E12.5-E14.5. (Control) values were pooled from heterozygote and wild-type embryos, which yielded equivalent results. 
ever, their total number was greatly reduced. Although committed erythroid precursors did represent a normal proportion of mutant liver cells (Fig. 6a), perhaps because these precursors represent early immigrants from the yolk sac (Medvinsky et al. 1993; Dzierzak and Medvinsky 1995), their calculated total number in the hypoplastic liver was reduced 30 -fold. For multilineage progenitors (Fig. 6b), however, there was a reduction in both the proportion of liver cells (5- to 6-fold) and their total number (150- to 180-fold). The even more primitive progenitors that can seed spleen colonies (CFU-S) were also somewhat rarer (Fig. $6 \mathrm{c}$ ), their total number being reduced $60-$ to 90 -fold. The contrasting normal level of CFU-S in the trunk (Fig. 6c), a transient source of hematopoietic stem cells (Medvinsky et al. 1993; Muller et al. 1994), indicates that the deficiency in hematopoietic progenitors was confined to the liver. Thus, the dearth of enucleated erythrocytes in the blood reflects greatly impaired liver hematopoiesis.

\section{$\mathrm{Hlx}^{-1-}$ cells can restore the} hematopoietic compartment

Because the Hlx gene is expressed in B lymphoid and myelomonocytic cells (Allen et al. 1991), it was important to determine whether the hematopoietic deficiency
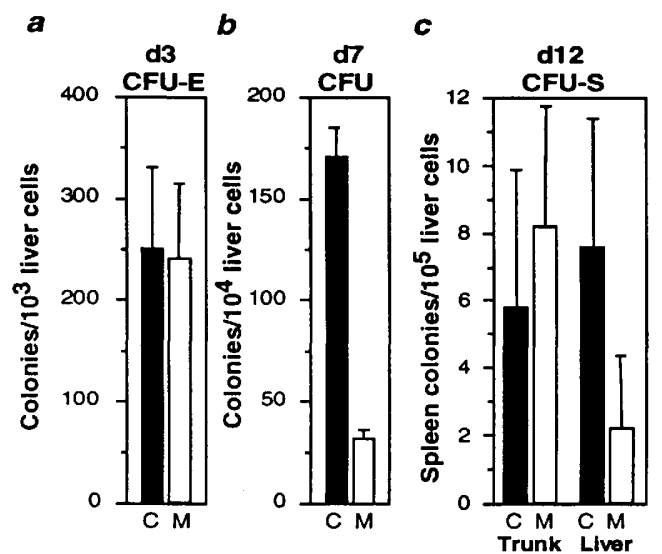

Reduction in total colonies in liver: 30 fold $\quad 150-180$ fold

$60-90$ fold

Figure 6. Colony assays determining the frequency of hematopoietic progenitors among E12.5 liver cells. C denotes control $(+1+$ or $+/-)$ and $M$ mutant $(-/-)$ embryos. $|a|$ Committed erythroid precursors (d3 CFU-E), assessed as the colonies that develop by day 3 in methylcellulose cultures (Metcalf 1984) in the presence of erythropoietin $(4 U / \mu l)$. (b) Multilineage colonies (d7 CFU), those that develop by day 7 in the presence of optimal concentrations of erythropoietin, IL-3 and stem cell factor. For $a$ and $b, n=5$ for controls and 4 for mutants. $(c) \mathrm{d} 12$ CFU-S, assessed by colonies present in the spleens of lethally irradiated adult mice 12 days after injection of two animals per sample with fetal liver $\left(5 \times 10^{4}\right.$ cells $)$ or the remaining trunk ( $n=9$ embryos). The fall in absolute numbers of hematopoietic progenitors in the liver shown at the bottom was calculated for each colony type assuming that the mutant liver contained $3 \%$ of the wild-type number of total cells (see text).

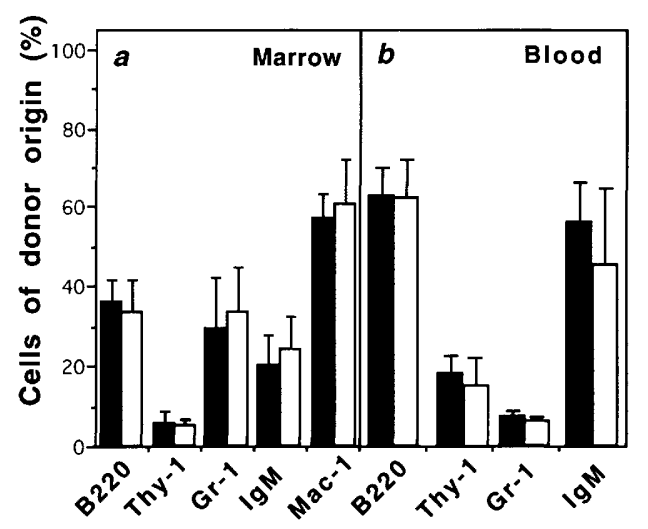

Figure 7. Retention of long-term multilineage-repopulating activity by $H l_{x^{-1-}}$ hematopoietic stem cells. Irradiated normal mice (Ly5.1) were transplanted with cells from the liver of a normal or mutant E13.5 embryo (Ly5.2). After 15 weeks, recipients (solid bars) controls; (open bars) mutants containing $>90 \%$ Ly $5.2^{+}$(donor-origin) peripheral blood cells were sacrificed, and their hematopoietic tissues subjected to two-color flow cytometric analysis for the presence of Ly5.2 and lineagespecific surface markers. For each marker, $4-6$ recipients of control and mutant cells were analyzed.

was in part intrinsic to the hematopoietic compartment. To resolve this issue, we compared the ability of $\mathrm{Hlx}^{-1-}$ and control fetal liver cells to reconstitute long-term hematopoiesis in lethally irradiated normal mice. The transplants rescued most recipients, and $80-100 \%$ of their blood cells bore the donor surface marker Ly5.2. Flow cytometric analyses 15 weeks after transplantation of the cell types in recipient bone marrow and blood (Fig. 7), as well as thymus and spleen (not shown) revealed that $\mathrm{HlX}^{-/-}$cells had contributed as effectively as wildtype cells to every hematopoietic compartment assessed. These included B lymphoid cells $\left(\mathrm{B} 220^{+}\right)$and their mature progeny $\left(\mathrm{IgM}^{+}\right.$cells), $\mathrm{T}$ lymphocytes $\left(\mathrm{Thy}-1^{+}\right)$and cells of the myelomonocytic lineages $\left(\mathrm{Gr}-1^{+}\right.$and/or $\mathrm{Mac}^{-1}{ }^{+}$.

The long-term repopulating ability of $\mathrm{Hl}^{-1-}$ cells was confirmed by the capacity of bone marrow cells from primary recipients to fully replenish the blood lineages of secondary recipients. Because the proportion of $H \mathrm{x}^{-1-}$ (i.e., Ly5. $2^{+}$) cells remained as high in secondary as in primary recipients, mutant stem cells in the primary bone marrow must have competed effectively with residual wild-type cells in the second transplant. Thus, we have found no evidence that Hlx ablation compromises hematopoietic potential.

Importantly, not only did $\mathrm{Hlx}^{-1-}$ stem cells generate a full complement of the lymphoid and myelomonocytic cells that normally express Hlx (Allen et al. 1991), but those cell types appeared to retain normal function. $H l x^{-1-}$ lymphoid cells purified from the spleens of reconstituted mice proliferated normally in response to the B-cell mitogens lipopolysaccharide and CD40, as well as to the T-cell mitogen Con A /see Materials and methods). Similarly, $\mathrm{Hlx}^{-1-}$ bone marrow cells pro- 
duced, in the presence of appropriate cytokines, myeloid colonies that were normal in number, appearance and composition. Finally, bone marrow-derived $\mathrm{Hlx}^{-1-}$ macrophages that were presented with microbeads exhibited normal phagocytic activity. Thus, we have found no evidence for an intrinsic defect in $\mathrm{Hlx}^{-1-}$ hematopoietic cells. It follows that the anemia in mutant embryos and the dearth of progenitors cells in their liver must be due largely, if not entirely, to an inability of the minute liver to adequately support proliferation of primitive hematopoietic cells.

\section{Discussion}

Our findings establish a vital role for the divergent homeo box gene Hlx in the development of the liver and gut. Animals heterozygous for a targeted mutation of $H l x$ appeared normal in every respect. In $H l^{-1-}$ embryos, whereas the specification and early morphogenesis of the viscera appeared normal, neither the liver nor the gut underwent the subsequent dramatic expansion characteristic of normal organogenesis. Mutant embryos also developed severe anemia (see below), but the visceral defects cannot be secondary to the anemia, because anemia became notable only at E13.5, well after the liver (and gut) deficiencies appeared, and because other mice with a fetal hematopoietic deficiency, such as those bearing an interrupted myb gene (Mucenski et al. 1991), lack visceral abnormalities. Consequently, the striking and fully penetrant visceral disturbance created by $H l x$ ablation provides new insight into the genetic control of organogenesis.

\section{Control by Hlx of visceral mesenchymal-epithelial interaction}

The visceral defects in these mice correlate well with the early pattern of $H{ }^{x}$ expression in embryos. Expression is first detected by in situ hybridization at E9.5 in splanchnic mesoderm caudal to the level of the heart, and then becomes prominent in mesenchyme of both the septum transversum into which the liver expands and the mesenchyme surrounding the midgut and hindgut epithelia (Lints et al. 1996). Because Hlx is not expressed in the epithelia themselves, our findings strongly suggest that $H l x$ controls a mesenchymal-epithelial interaction critical for liver and gut expansion. This interaction is most likely mediated by mitogenic factors or matrix components secreted from the mesenchyme.

$H l x$ might control expression of the mitogenic signal directly, or influence it more indirectly by regulation of a broader aspect of mesodermal differentiation. Although some subtle effects on mesodermal differentiation in the mutant animals cannot be ruled out, three observations suggest that its development is substantially normal. First, visceral mesenchyme in mutant embryos formed an intestinal sheath of normal histological appearance, where the precursors of the connective tissue and muscular layers of the gut were readily discern- ible. Second, the mutant liver contained endothelial cells lining vessels, as well as a capsule, both of mesenchymal origin. These two features reflect the plasticity of visceral mesenchyme and indicate that it has differentiated appropriately in response to the environment of specific organs. Third, the mutant liver supported hematopoiesis (albeit at a reduced level), a feature attributable in part to liver endothelial cell function (Houssaint 1980). If differentiation of the mesodermal component of the viscera is normal, as it appears to be, Hlx may well regulate the mesenchymal inductive signals directly.

The specification, morphogenesis, and differentiation of all the viscera depend critically on a bidirectional molecular dialog (inductive signaling) between organ endoderm and its associated mesenchyme (Birchmeier and Birchmeier 1993). Those interactions are known to be critical for liver development, which has been studied in detail, particularly in the chick, by Le Douarin and others (Willier and Rawles 1931; Wolff 1968; Le Douarin 1975; Houssaint 1980; Zaret 1994). The model in Figure 8 relates Hlx action to stages of liver ontogeny. The inductive event that initiates liver development occurs at pre-somite stages when midgut endodermal cells that will form the liver contact the cardiogenic mesoderm (Fig. 8, stage A). This mesenchyme must provide a necessary commitment signal, because endoderm grafted onto the chick chorioallantoic membrane develops liver parenchymal cells only if cardiogenic mesoderm is also present (Le Douarin 1975). This mesodermal signal is assumed to be instructive (Gurdon 1987), committing naive endoderm to a liver fate (Fukuda-Taira 1981). Consistent with the lack of significant Hlx expression in the cardiogenic mesoderm, liver specification was not affected in $H l^{-1-}$ embryos.

Subsequent stages of liver ontogeny (Fig. 8, stages B and $C$ ) require inductive interaction with the septum transversum. This mesenchyme at the base of the heart surrounds the liver endodermal rudiment and expresses $H l x$ at a high level. In response to a signal from the septum transversum, liver endoderm undergoes an epithelial-mesenchymal transition to form a diverticulum (stage B) and then proliferates into the mesenchyme to form liver cords and the liver bud (stage C). Coincident with these processes, liver differentiation begins, as exemplified by the expression of $\alpha$-fetoprotein, albumin, and HNF-4 (Makover et al. 1989; Cascio and Zaret 1991; Duncan et al. 1994). The critical role of this second mesenchymal signal is demonstrated by evidence that a liver endodermal rudiment placed in explant culture will neither proliferate nor differentiate in the absence of hepatic mesenchyme (Le Douarin 1975). Because $H l x^{-1-}$ embryos exhibited a normal diverticulum and evidence of liver-specific gene expression, Hlx cannot be essential for either differentiation or early morphogenesis (stage B).

The crucial role of $H l_{x}$ in liver ontogeny must instead lie at a third stage, that of organ expansion (Fig. 8, stage C). We propose that $H l_{x}$ expression controls secretion from mesenchyme of the proliferative signal for liver ep- 
Figure 8. Role of $H l_{X}$ in liver development. In this model, the phases of liver ontogeny are controlled by three distinct mesenchymal signals (denoted by arrows). Hlx expression (yellow) in the septum transversum (and later in liver capsule and endothelial cells) governs the mitogenic signal for liver growth (stage $C$ ) but not those needed for commitment istage $A$ ) or differentiation and early morphogenesis (stage $B \mid$. (Stage A) Prior to Hlx expression, the abutting cardiogenic mesoderm $(\mathrm{cm})$ commits midgut endoderm (me) to a liver fate (purple). (Stage B) A signal from the surrounding septum transversum mesenchyme $(\mathrm{stm})$ causes gut endodermal (ge) hepatic progenitors to undergo an epithelial-mesenchymal transition and form the liver diverticulum (ld) and hepatic cords. (Stage $C$ ) In response to the mitogenic signal controlled by Hlx expression, proliferation of hepatic cords into the septum transversum forms the liver bud. As the organ greatly expands, it is colonized by hematopoietic stem cells (hp).

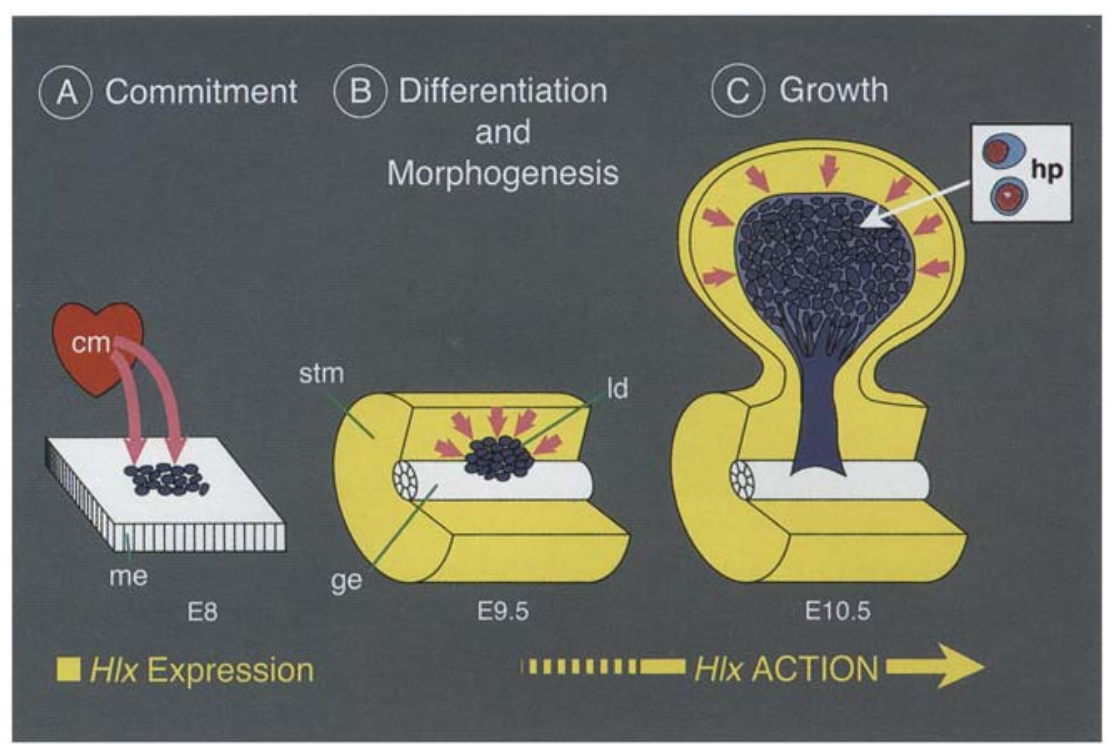

ithelia defined by the classical work. Our evidence that the control of liver expansion is separable from that of differentiation refines the classical view, implicating at least three distinct inductive events in liver development. Indeed, the studies of Le Douarin hinted that the proliferative and differentiative signals secreted by liver mesenchyme might be distinct (Le Douarin 1975). Our finding that $H l_{x}$ disruption ablates only the growth phase strongly favors the view that visceral organogenesis proceeds by stepwise inductive interactions under separate genetic control.

Does Hlx control a common proliferative signal for liver and gut? The mesenchymal signal for liver development can be supplied by different mesenchymal sources. In explant experiments, liver mesenchyme can be replaced by gut, somatic or lung mesenchyme but not those of the head or kidney (Le Douarin 1975). Notably, these sources correlate well with the expression of $H / x$ transcripts in liver, gut, lung, and pericardial mesoderm, and their absence in head and kidney (Lints et al. 1996). It therefore seems likely that the mitogenic factor for liver growth is also secreted from gut mesenchyme and indeed that gut proliferation (elongation) is stimulated by this same factor. The gut defects in $\mathrm{Hl}^{-1-}$ mice would strongly support this notion. Hence we propose that $H l_{x}$ controls a factor required for proliferation of both liver and gut epithelia.

\section{Does Hlx function in hematopoiesis?}

A role for Hlx in hematopoiesis has been anticipated from the initial finding that its expression within that compartment is confined to the B lymphoid and myelomonocytic lineages (Allen et al. 1991). Some support for this notion was provided by evidence that enforced expression of the gene could modify the phenotype of several hematopoietic cell lines (Deguchi et al. 1992; Allen and Adams 1993), as well as disturb T-cell development in transgenic mice (Deguchi et al. 1993; Allen et al. 1995). Nevertheless, we have as yet found no convincing evidence for an intrinsic defect in $\mathrm{Hl}^{-1-}$ hematopoietic cells. Hematopoietic stem cells in the fetal liver of $\mathrm{Hlx}^{-1-}$ mice could fully reconstitute the hematopoietic compartment of irradiated normal mice. Multilineage reconstitution was stable and the proportion of $\mathrm{Hlx}^{-1-}$ blood cells was not reduced in secondary recipients. Moreover, $H l_{x}^{-1-}$ lymphoid and myeloid cells from recipient animals have been competent by all tests so far applied.

To reconcile these observations, we suggest that $H l x$ function in normal B lymphoid and myelomonocytic cells is at least very largely redundant with that of another homeo box gene, such as the related Hex gene, which has a similar hematopoietic expression pattern (Bedford et al. 1993). Redundancy with other homeo box genes may well also account for the lack of overt defects in other sites of Hlx expression, such as the lungs, muscles, and sclerotome.

Because Hlx ablation did not compromise the developmental potential of hematopoietic stem and progenitor cells, it seems highly likely that the reduced fetal hematopoiesis and consequent severe anemia observed in $\mathrm{Hlx}^{-1-}$ embryos reflects an inadequate liver microenvironment. A vast reduction in hematopoietic output would be expected for an organ only $3 \%$ the normal size. Presumably, the number of niches that can support hematopoietic foci is greatly decreased. The defect in liver support function, however, may well be qualitative as well as quantitative, because the numbers of some early 
hematopoietic progenitors were disproportionately reduced in mutant liver (Fig. 6B,C). Although that difference might reflect a drop in the total number of hematopoietic stem cells capable of entering the liver, it seems more likely that liver stromal (endothelial) cells simply produce less of a cytokine or matrix component needed for robust hematopoiesis.

\section{Nature of the mitogenic signal for visceral epithelia}

Is the growth-stimulatory factor regulated by $H l_{x}$ among mitogens known to be active on hepatocytes? One plausible candidate is hepatocyte growth factor/scatter factor (HGF/SF), a potent mitogen expressed in visceral mesenchyme during development (for review, see Rosen et al. 1994). Because HGF/SF can also induce an epithelialmesenchymal transition (scattering) in vitro, it conceivably might guide formation of the diverticulum during early liver morphogenesis. Recent evidence, however, demonstrates that mice unable to make HGF/SF or its receptor c-Met display only limited liver hypoplasia (Bladt et al. 1995; Schmidt et al. 1995), or, in a separate study, none discernible (Uehara et al. 1995). Hence, loss of HGF/SF expression cannot account for the severe liver defect seen in $\mathrm{HlX}^{-/-}$mice. Notably, the widespread apoptosis apparent in the liver of mice with impaired HGF/SF signaling (Bladt et al. 1995; Schmidt et al. 1995) was not observed in the $H_{x^{-1}}$ - liver. This difference favors the view that the major role of HGF/SF lies not in early stages of liver development but in maintenance of hepatocyte survival and/or liver regeneration (Shiota et al. 1994). TGF- $\alpha$ and TGF- $\beta 1$, two other factors implicated in liver growth or regeneration, also appear unlikely to account for the Hlx-controlled signal, because targeted disruption of those genes did not produce overt liver hypoplasia (Kulkarni et al. 1993; Mann et al. 1993). Hence, the mesenchymal signal by which Hlx controls epithelial growth may involve novel factors and/or a combination of factors.

Vital organogenic roles for homeo box genes are emerging. It is now known that the insulin promoter factor 1 gene is crucial for pancreas development (Jonsson et al. 1994); Hox-11, a relative of $H l x$, for spleen formation (Roberts et al. 1994; Dear et al. 1995); Pax-6 for eye formation (Halder et al. 1995), and Nkx2-5 for heart development (Lyons et al. 1995). Unique among this group, $H l x$ appears to regulate an inductive process, the mesenchymal-epithelial interaction essential for expansion of the liver and gut. There are several precedents for control of mesenchyme-epithelial interactions by homeo box genes during Drosophila gut development, where growth factors of the transforming growth factor- $\beta$ (TGF- $\beta$ ) and Wnt families mediate the interaction (Andrew and Scott 1992). The availability of $\mathrm{Hlx}^{-1-} \mathrm{em}$ bryos should aid identification of the relevant mammalian factors and enhance understanding of this key step in organogenesis. An intriguing possibility is that the same mesenchyme-derived growth factors control expansion of both the liver parenchymal cells and the hematopoietic stem cells that seed the fetal liver.

\section{Materials and methods}

\section{Gene targeting}

The targeting vector is shown in Figure 1A. The linearized vector was electroporated into E14 ES cells (Hooper et al. 1987) as described (Lyons et al. 1995). Southern blots on DNA from 200 G418-resistant clones revealed 5 bearing a HindIII fragment diagnostic of the targeted allele (see Fig. 1A), but 3 also contained extraneous copies of the vector, revealed by the neo probe. Injection of the two other lines into $/ \mathrm{C} 57 \mathrm{BL} / 6 \times \mathrm{C} 57 \mathrm{BL} / 10 \mid \mathrm{F}_{1}$ blastocysts and breeding of the resulting chimeras yielded one line that transmitted the mutant allele through the germ line. PCR genotyping was performed with primers 5'-GCAGATAAGCCATTCTAGTGGG-3' (sense) and 5'-AGGATTTAAGGAGTCCTGACAC- $3^{\prime}$ (antisense) to detect the wild-type allele, and the sense primer in combination with $5^{\prime}$-GCTCCAGACTGCCTTGGGAAAA-3' (antisense) for the mutant allele. PCR conditions were as described (Lyons et al. 1995).

\section{Histology on embryos and in situ hybridization}

To time embryonic development, mating pairs were set up overnight, and the appearance of a vaginal plug in the morning was taken as E0.5. Staging of embryos was according to Kaufman 1992.

For histology, embryos were fixed in paraformaldehyde, embedded in paraffin blocks, sectioned, and stained with hematoxylin and eosin. Histological examination was carried out on four $H x^{-1-}$ embryos of E9.5, seven of E10.5, four of E11.5, and two of E14.5 as well as comparable numbers of $\mathrm{Hlx}^{+1-}$ or $\mathrm{Hlx}^{+1+}$ littermates. In situ hybridization was performed with ${ }^{33} \mathrm{P}$-radiolabeled complementary RNA probes as described previously (Lyons et al. 1995).

\section{Enumeration of liver cells}

Liver cell numbers were estimated for $12 \mathrm{Hlx}^{-1-}$ and 14 normal littermates of E12.5. Single-cell suspensions were prepared by passing of the chilled liver through a 20 -gauge needle $\sim 10$ times in cold isotopic buffered medium containing $4 \%$ fetal calf serum. Viable cell numbers were then determined by trypan blue exclusion in a hemocytometer. The proportion of viable cells was as high in the mutant as the normal liver. Whereas the normal liver yielded $3.6 \pm 1.4(\mathrm{SD}) \times 10^{6}$ cells, the mutant liver gave only $1.1 \pm 0.6 \times 10^{5}$ cells. Thus, the mutant dorsal lobe contained $\sim 3 \%$ of the normal cell number; the number in the very indistinct ventral lobe of the mutants was considered negligible.

\section{Colony assays for hematopoietic progenitor cells}

Cell suspensions were made from normal or mutant liver, and viable cells (those excluding trypan blue) enumerated in a hemocytometer. For in vitro colony assays $1 \times 10^{4}$ cells from E12.5 liver were plated in duplicate in $35-\mathrm{mm}$ plates in $1 \mathrm{ml}$ of semisolid Iscove's modified Dulbecco's medium containing $0.8 \%$ methylcellulose (Methocel 65HG, Fluka Chemie, Switzerland), $20 \%$ FCS and optimal concentrations of appropriate growth factors (see Fig. 6). Plates were incubated at $37^{\circ} \mathrm{C}$ in a humidified atmosphere of $5 \% \mathrm{CO}_{2}$ in air. For erythroid precursors, plates were stained after 3 days with $0.2 \%$ benzidine dihydrochloride in $0.5 \%$ acetic acid (supplemented with $0.4 \mathrm{ml} 30 \% \mathrm{H}_{2} \mathrm{O}_{2}$ per $100 \mathrm{ml}$ prior to use) and numbers of erythroid colonies $\geqslant 4$ cells determined by use of a dissection microscope. For mixed hematopoietic precursors, total colonies $(>50$ cells) were enumerated after seven days. Representative colonies were picked, 
transferred to glass slides, stained using Diff-Quick (Lab-Aids, Narrabeen, Australia), which yields a Wright-Giemsa-like stain, and the cell types present were identified microscopically. Plates were also stained with benzidinie to estimate the number of colonies containing hemaglobinized cells.

To assay formation of spleen colonies, the recipients were age-matched 6- to 12-week-old female C57BL/6 mice. They were lethally irradiated $(10 \mathrm{~Gy})$ and injected intravenously with $5 \times 10^{4}$ normal or mutant E12.5 fetal liver cells or cells of the remaining trunks. After 12 days the recipients were killed and their spleens dissected and treated with Telleysviczki fixture (20:1:1 ethanol/formalin/glacial acetic acid). Macroscopic spleen colonies were then counted by use of a dissection microscope at low magnification.

\section{Hematopoietic reconstitution and functional tests on $\mathrm{Hlx}^{-1-}$ cells}

Lethally irradiated ( $10 \mathrm{~Gy}$ ) 6- to 12-week-old female C57BL/6Ly5.1 mice were injected intravenously with liver cells from a normal or mutant E13.5 embryo (Ly5.2). After 15 weeks, the hematopoietic tissues of recipients that contained $>90 \%$ Ly5.2 $2^{+}$blood cells were analyzed for Ly5.2 and lineage-specific surface markers as described previously (Szilvassy and Cory 1994).

For in vitro tests, $2 \times 10^{6}$ to $5 \times 10^{6}$ control cells from the spleen or bone marrow of a mouse reconstituted to $>90 \%$ with Ly5.2 $2^{+}$cells were purified further for that marker by sorting on a FACStar-Plus (Becton Dickinson). The proliferative potential of $B$ and $T$ cells was then assessed by stimulation of $5 \times 10^{4}$ sorted Ly5.2 $2^{+}$spleen cells, in $100 \mu$ l of Dulbecco's modified Eagle medium supplemented with $100 \mu \mathrm{M}$ L-asparagine, $50 \mu \mathrm{M}$ 2 -mercaptoethanol and $10 \%$ fetal bovine serum, with lipopolysaccharide $(20 \mu \mathrm{g} / \mathrm{ml})$, CD40 ligand $(1 \mu \mathrm{g} / \mathrm{ml})$, or ConA $(2 \mu \mathrm{g})$ $\mathrm{ml})$. Upon incubation for $18 \mathrm{or} 66 \mathrm{hr}$, followed by a 6 -hr pulse of $\left.{ }^{3} \mathrm{H}\right]$ thymidine, $\mathrm{Hlx}^{-1-}$ cells incorporated as much label as control cells. Colony forming ability of Ly5.2 $2^{+}$bone marrow cells was assessed by growth in agar in the presence of optimal amounts of (1) macrophage-colony stimulating factor (M-CSF), (2) granulocyte-macrophage (GM)-CSF, (3) GM-CSF plus stem cell factor (SCF), or (4) SCF plus interleukin-3 (IL-3) (Metcalf 1984).

For tests of phagocytic activity, $H \mathrm{~lx}^{-1-}$ macrophages were derived from the bone marrow of reconstituted mice by growing $2 \times 10^{5}$ marrow cells sorted for Ly5.2 for 5-7 days in M-CSF. Phagocytic activity was tested by microscopic examination of cells incubated overnight with $6 \mu \mathrm{m}$ plastic beads.

\section{Acknowledgments}

We are grateful to Drs. A. Strasser, N. Nicola, M. Dziadek, and G. Schreiber for reagents and to Drs. D. Metcalf, T. Metz, G. McArthur, S. Cory, C. Biben, and D. Huang for advice. This work was supported by the National Health and Medical Research Council (Australia) and the U.S. National Institutes of Health (HD26024 and CA12421). B.H. was supported by a fellowship from the Deutsche Forschungsgemeinschaft, while R.P.H. holds an Australian Research Council Research Fellowship.

The publication costs of this article were defrayed in part by payment of page charges. This article must therefore be hereby marked "advertisement" in accordance with 18 USC section 1734 solely to indicate this fact.

\section{References}

Allen, J.D. and J.M. Adams. 1993. Enforced expression of $H{ }^{x}$ homeobox gene prompts myeloid cell maturation and al- tered adherence properties of T cells. Blood 81: 3242-3251. Allen, J.D., T. Lints, N.A. Jenkins, N.G. Copeland, A. Strasser, R.P. Harvey, and J.A. Adams. 1991. Novel murine homeo box gene on chromosome 1 expressed in specific hematopoietic lineages and during embryogenesis. Genes \& Dev. 5: 509-520.

Allen, J.D., A.W. Harris, M.L. Bath, A. Strasser, R. Scollay, and J.A. Adams. 1995. Perturbed T- and B-cell development in mice expressing an $\mathrm{Hlx}$ homeobox transgene. I. Immunol. 154: 1531-1542.

Andrew, D.J. and M.P. Scott. 1992. Downstream of the homeotic genes. New Biol. 4: 5-15.

Barad, M., T. Jack, R. Chadwick, and W. McGinnis. 1988. A novel, tissue-specific, Drosophila homeobox gene. EMBO $J$. 7: 2151-2161.

Bard, J.B.L. 1992. The development of the mouse kidney-embryogenesis writ small. Curr. Opin. Genet. Dev. 2: 589-595.

Bedford, F.K., A. Ashworth, T. Enver, and L.M. Wiedemann. 1993. HEX: A novel homeobox gene expressed during haematopoiesis and conserved between mouse and human. $\mathrm{Nu}$ cleic Acids Res. 21: 1245-1249.

Beg, A.A., W.C. Sha, R.T. Bronson, S. Ghosh, and D. Baltimore. 1995. Embryonic lethality and liver degeneration in mice lacking the RelA component of NF-kappa-B. Nature 376: $167-170$.

Birchmeier, C. and W. Birchmeier. 1993. Molecular aspects of mesenchymal-epithelial interactions. Annu. Rev. Cell Biol. 9: $511-540$.

Bladt, F., D. Riethmacher, S. Isenmann, A. Aguzzi, and C. Birchmeier. 1995. Essential role for the c-met receptor in the migration of myogenic precursor cells into the limb bud. $\mathrm{Na}$ ture 376: 768-771.

Cascio, S. and K.S. Zaret. 1991. Hepatocyte differentiation initiates during endodermal-mesenchymal interactions prior to liver formation. Development 113: 217-225.

Corcoran, L.M. and M. Karvelas. 1994. Oct-2 is required early in $T$ cell-independent $B$ cell activation for Gl progression and for proliferation. Immunity 1: 635-645.

Dear, T.N., W.H. Colledge, M.B.L. Carlton, I. Lavenir, T. Larson, A.J.H. Smith, A.J. Warren, M.J. Evans, M.V. Sofroniew, and T.H. Rabbitts. 1995. The Hox11 gene is essential for cell survival during spleen development. Development 121: 2909-2915.

Deguchi, Y., C. Thevenin, and J.H. Kehrl. 1992. Stable expression of HB24, a diverged human homeobox gene, in T lymphocytes induces genes involved in $T$ cell activation and growth. J. Biol. Chem. 267: 8222-8229.

Deguchi, Y., D. Agus, and J.H. Kehrl. 1993. A human homeobox gene, HB24, inhibits development of $\mathrm{CD}^{+} \mathrm{T}$ cells and impairs thymic involution in transgenic mice. J. Biol. Chem. 268: 3646-3653.

Del Buono, R., K.A. Flemming, A.L. Morey, P.A. Hall, and N.A. Wright. 1992. A nude mouse xenograft model of fetal intestine development and differentiation. Development 114: 67-73.

Duncan, S.A., K. Manova, W.S. Chen, P. Hoodless, D.C. Weinstein, R.F. Bachvarova, and J.J.E. Darnell. 1994. Expression of transcription factor HNF-4 in the extraembryonic endoderm, gut, and nephrogenic tissue of the developing mouse embryo: HNF-4 is a marker for primary endoderm in the implanting blastocyst. Proc. Natl. Acad. Sci. 91: 7598-7602.

Dzierzak, E. and A. Medvinsky. 1995. Mouse embryonic hematopoiesis. Trends Genet. 11: 359-366.

Fukuda-Taira, S. 1981. Hepatic induction in the avian embryo: Specificity of reactive endoderm and inductive mesoderm. $J$. Embryol. Exp. Morphol. 63: 111-125. 
Gavrieli, Y., Y. Sherman, and S.A. Ben-Sasson. 1992. Identification of programmed cell death in situ via specific labeling of nuclear DNA fragmentation. J. Cell Biol. 119: 493-501.

Grobstein, C. 1953. Inductive epithelio-mesenchymal interactions in cultured organ rudiments of the mouse. Science 118: 52-55.

Gurdon, J.B. 1987. Embryonic induction-Molecular prospects. Development 99: 285-306.

Halder, G., P. Callaerts, and W.J. Gehring. 1995. Induction of ectopic eyes by targeted expression of the eyeless gene in Drosophila. Science 267: 1788-1792.

Hooper, M., K. Hardy, A. Handyside, S. Hunter, and M. Monk. 1987. HPRT-deficient (Lesch-Nyhan) mouse embryos derived from germline colonization by cultured cells. Nature 326: 292-295.

Houssaint, E. 1980. Differentiation of the mouse hepatic primordium. I. An analysis of the tissue interactions in hepatocyte differentiation. Cell Differ. 9: 269-279.

Jonsson, J., L. Carlsson, T. Edlund, and H. Edlund. 1994. Insulinpromoter-factor 1 is required for pancreas development in mice. Nature 371: 606-609.

Kaufman, M.H. 1992. The atlas of mouse development. Academic Press, London, UK.

Kedinger, M., P.M. Simon-Assmann, B. Lacroix, A. Marxer, H.P. Hauri, and K. Haffen. 1986. Fetal gut mesenchyme induces differentiation of cultured intestinal endodermal and crypt cells. Dev. Biol. 113: 474-483.

Kriedberg, J.A., H. Sariola, J.M. Loring, M. Maeda, J. Pelletier, D. Housman, and R. Jaenisch. 1993. WT-1 is required for early kidney development. Cell 74: 679-691.

Krumlauf, R. 1994. Hox genes in vertebrate development. Cell 78: 191-201.

Kulkarni, A.B., C.G. Huh, D. Becker, A. Geiser, M. Lyght, K.C. Flanders, A.B. Roberts, M.B. Sporn, J.M. Ward, and S. Karlsson. 1993. Transforming growth factor $\beta 1$ null mutation in mice causes excessive inflammatory response and early death. Proc. Natl. Acad. Sci, 90: 770-774.

Le Douarin, N.M. 1975. An experimental analysis of liver development. Med. Biol. 53: 427-455.

Lin, C., S.-C. Lin, C.-P. Chang, and M.G. Rosenfeld. 1992. Pit1-dependent expression of the receptor for growth hormone releasing factor mediates pituitary cell growth. Nature 360: $765-768$.

Lints, T.J., L. Hartley, L.M. Parsons, and R.P. Hartley. 1996. Mesoderm-specific expression of the divergent homeobox gene $H l_{x}$ during murine embryogenesis. Dev. Dynam. (in press).

Lyons, I., L.M. Parsons, L. Hartley, R. Li, J. Andrews, L. Robb, and R.P. Harvey. 1995. Myogenic and morphogenetic defects in the heart tubes of murine embryos lacking the homeo box gene Nkx2-5. Genes \& Dev. 9: 1654-1666.

Makover, A., D.R. Soprano, M.L. Wyatt, and D.S. Goodman. 1989. An in situ-hybridization study of the localization of retinol-binding protein and transthyretin messenger RNAs during fetal development in the rat. Differentiation 40: 1725.

Mann, G.B., K.J. Fowler, D. Grail, and A.R. Dunn. 1993. Identification of germ-line chimeras by polymerase chain reaction and isoenzyme analysis of mouse spermatozoa. I. Reprod. Fertil. 99: 505-512.

Medvinsky, A.L., N.L. Samoylina, A.M. Muller, and E.A. Dzierzak. 1993. An early pre-liver intraembryonic source of CFU-S in the developing mouse. Nature 364: 64-67.

Metcalf, D. 1984. The hematopoietic colony stimulating factors. Elsevier, Amsterdam, Netherlands.

Mucenski, M.L., K. McLain, A.B. Kier, S.H. Swerdlow, C.M.
Schreiner, T.A. Miller, D.W. Pietryga, W. Scott Jr., and S.S. Potter. 1991. A functional c-myb gene is required for normal murine fetal hepatic hematopoiesis. Cell 65: 677-689.

Muller, A.M., A. Medvinsky, J. Strouboullis, F. Grosveld, and E. Dzierak. 1994. Development of hematopoietic stem cell activity in the mouse embryo. Immunity 1: 291-301.

Roberts, C.W.M., J.R. Shutter, and S.J. Korsmeyer. 1994. Hox 11 controls the genesis of the spleen. Nature 368: 747-749.

Rosen, E.M., S.K. Nigam, and I.D. Goldberg. 1994. Scatter factor and the c-Met receptor: A paradigm for mesenchymal/epithelial interaction. J. Cell Biol. 127: 1783-1787.

Rutter, W.J., R.L. Pictet, J.D. Harding, J.M. Chirgwin, R.J. MacDonald, and A.E. Przybyla. 1978. An analysis of pancreatic development: Role of mesenchymal factor and other extracellular factors. In Molecular Control of Proliferation and Differentiation (ed. J. Papaconstantinou and W. Rutter), pp. 205-227. Academic Press, New York, NY.

Schmidt, C., F. Bladt, S. Goedecke, V. Brinkmann, W. Zschiesche, M. Sharpe, E. Gheradi, and C. Birchmeier. 1995. Scatter factor/hepatocyte growth factor is essential for liver development. Nature 373: 699-702.

Shiota, G., T.C. Wang, T. Nakamura, and E.V. Schmidt. 1994. Hepatocyte growth factor in transgenic mice: Effects on hepatocyte growth, liver regeneration and gene expression. Hepatology 19: 962-972.

Szilvassy, S.J. and S. Cory. 1994. Efficient retroviral gene transfer to purified long-term repopulating hematopoietic stem cells. Blood 84: 74-83.

Thomas, K.R. and M.R. Cappechi. 1987. Site-directed mutagenesis by gene targeting in mouse embryo-derived stem cells. Cell 51: 503-512.

Thomas, T., B.R. Southwell, G. Schreiber, and A. Jaworowski. 1990. Plasma protein synthesis and secretion in the visceral yolk sac of the fetal rat: Gene expression, protein synthesis and secretion. Placenta 11: 413-430.

Uehara, Y., O. Minowa, C. Mori, K. Shiota, J. Kuno, T. Noda, and N. Kitamura. 1995. Placental defect and embryonic lethality in mice lacking hepatocyte growth factor/scatter factor. Nature 373: 702-705.

van den Hoff, M.J.B., J.L.M. Vermeulen, P.A.J. De Boer, W.H. Lamers, and A.F. Moorman. 1994. Developmental changes in the expression of the liver-enriched transcription factors LF-B1, C/EBP, DBP and LAP/LIP in relation to the expression of albumin, alpha-fetoprotein, carbamoylphosphate synthase and lactase mRNA. Histochem. J. 26: 20-31.

Wessells, N.K. and J.H. Cohen. 1967. Early pancreas organogenesis: Morphogenesis, tissue interactions, and mass effect. Dev. Biol 15: 237-270.

Willier, B.H. and M.E. Rawles. 1931. Developmental relations of the heart and liver in chorioallantoic grafts of whole chick blastoderms. Anatom. Rec. 48: 277-301.

Wolff, E. 1968. Specific interactions between tissues during organogenesis. Curr. Top. Dev. Biol. 3: 65-94.

Zaret, K.S. 1994. Early liver development. In Liver gene expression (ed. F. Tronche and M. Yaniv), pp. 3-16. Landes Co., Austin, TX. 


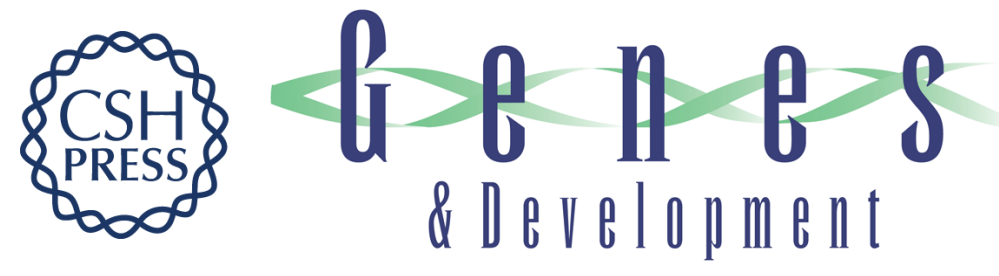

\section{HIx homeo box gene is essential for an inductive tissue interaction that drives expansion of embryonic liver and gut.}

B Hentsch, I Lyons, R Li, et al.

Genes Dev. 1996, 10:

Access the most recent version at doi:10.1101/gad.10.1.70

References This article cites 50 articles, 17 of which can be accessed free at: http://genesdev.cshlp.org/content/10/1/70.full.html\#ref-list-1

License

Email Alerting

Service

Receive free email alerts when new articles cite this article - sign up in the box at the top right corner of the article or click here.

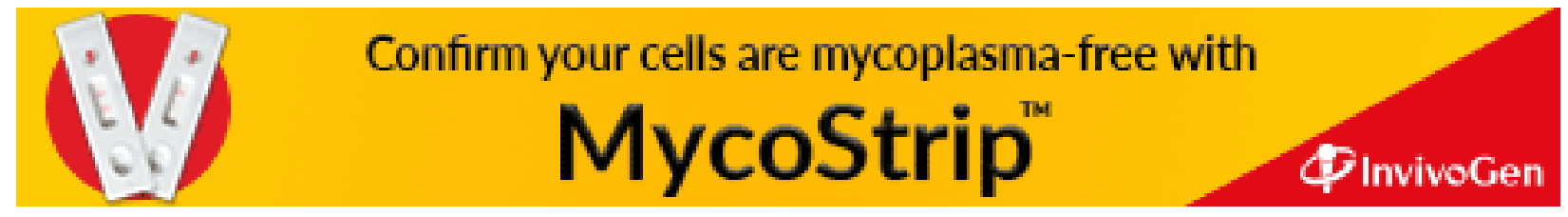

